\title{
A Systematic Review and a Meta-Analysis of Using Acupuncture for the Treatment of Nocturnal Enuresis
}

\author{
Anoush Azarfar ${ }^{1}$, Yalda Ravanshad ${ }^{2 *}$, Shahpour Badiei Aval ${ }^{3}$, Zhila Khamnian ${ }^{4}$ and Hassan Mehrad-Majd ${ }^{2}$ \\ ${ }^{1}$ Department of Pediatric, Faculty of Medicine, Mashhad University of Medical Sciences, Mashhad, Iran \\ ${ }^{2}$ Clinical Research Unit, Mashhad University of Medical Sciences, Mashhad, Iran \\ ${ }^{3}$ Chinese Medicine Traditional and Complementary, Faculty of Medicine, Mashhad University of Medical Sciences, Mashhad, Iran \\ ${ }^{4}$ Social Determinant of Health Research Center, Tabriz University of Medical Sciences, Tabriz, Iran
}

*Corresponding author: Yalda Ravanshad, Clinical Research Unit, Mashhad University of Medical Sciences, Mashhad, Iran, Tel: +989153017977; E-mail: Yalda.Ravanshad@gmail.com

Received Date: April 17, 2017; Accepted Date: April 28, 2017; Published Date: April 30, 2017

Copyright: ( 2017 Azarfar A, et al. This is an open-access article distributed under the terms of the Creative Commons Attribution License, which permits unrestricted use, distribution, and reproduction in any medium, provided the original author and source are credited.

\begin{abstract}
Background: Acupuncture has been an interesting portion of Traditional Chinese Medicine. Many studies have shown that pediatric acupuncture is also acceptable and feasible. Nocturnal enuresis (NE) is defined as evacuating the bladder during sleep in a child older than five years old. Acupuncture and laser acupuncture may be more effective than sham procedures at reducing enuresis and relapse rates; however, the evidence is weak. The purpose of this study is to evaluate the effect of acupuncture therapy in the treatment of nocturnal enuresis on randomized controlled trials (RCTs).
\end{abstract}

Method: An electronic literature search was conducted to identify appropriated trial studies. The outcomes were presented as relative risk, with $95 \%$ confidence intervals $(\mathrm{Cl})$.

Results: We found only seven trials that fulfilled our inclusion criteria. Only seven trials from five studies were included in meta-analysis. Final relative risk (RR) was not statistically significant (RR (range) $=1.312(0.939-1.832)$ ) but evidences from independent review of each study suggested effective roll of acupuncture in treatment of NE.

Conclusion: In summary, the results of this study show that acupuncture seems to be an effective treatment for $\mathrm{NE}$, but further large randomized trials are suggested.

Keywords: Meta-analysis; Acupuncture; Nocturnal enuresis

\section{Introduction}

Acupuncture has been an interesting portion of traditional Chinese medicine (TCM) for over 2000 years [1]. Acupuncture and its connected therapies, such as laser acupuncture, acupressure and electro-acupuncture, are used throughout East Asia to treat and prevent a great array of diseases. Acupuncture has been adopted by the Western world as complementary treatments for many diseases. Many studies have shown that pediatric acupuncture is acceptable and feasible [1,2]. Nocturnal enuresis (NE) is defined as evacuationof bladder during sleep in a child older than five years old [3]. It has two types: monosymptomatic nocturnal enuresis (MNE) with no urinary symptoms in daytime, and nonmonosymptomatic nocturnal enuresis (NMNE) which includes daytime urinary symptoms [4]. Nocturnal enuresis (NE) occurs in $15 \%$ to $20 \%$ of 5 -year-old children, $5 \%$ of 10 year-old children, and $1 \%$ to $2 \%$ of persons aged 15 years and older. Each year, 15\% of children suffering from NE are cured without any treatment. Nocturnal enuresis can cause significant distress for parents and children [1]. Three mechanisms were imaged for NE including: bladder over-activity, failure to awaken in response to bladder sensations, and excessive nocturnal urine production [5]. The current acceptable treatments for $\mathrm{NE}$ are oral pharmacological therapies, including desmopressin, tricyclics, and oxybutynin, and behavioral therapies [6]. Desmopressin has been proven to have reliable effects on one third of the unselected enuretic children. However, when the medication is not taken anymore, the clinical drug effects cannot be continued, and the side effects of drugs may cause the patients to oppose taking them for a long time [7]. Complementary and alternative medicine (CAM) widely helped to encounter the increasing demand for nonpharmacological approaches [6].

Acupuncture and laser acupuncture may be more effective than sham procedures at reducing enuresis and relapse rates; however, the evidence is weak [8]. Compared to formal treatment, safety and cost effectiveness of acupuncture cause the maintenance of patients' compliance [6]. The purpose of this study is to evaluate the effect of acupuncture therapy in the treatment of nocturnal enuresis on randomized controlled trials (RCTs).

\section{Literature Survey}

Alsharnoubi designed a RCT studies including 45 children with NE, patients were randomized into three equal groups (Table 1). A statistically significant higher cure rate was reported in laser acupuncture group $73.3 \%$, than other two groups. This study concluded that laser acupuncture is noninvasive, painless, with no side effects and its recurrence rate is very low which can be used as an alternative therapy for patients with NE [11]. 
Mogahed conducted a RCT study which included 50 children with NE who were randomly assigned to two groups of equal numbers. The results of this study suggested that low level laser acupuncture has an effect on bladder reservoir function and decreasing bedwetting in nocturnal enuresis [12].

The aim of MOURSY RCT study was to evaluate the efficacy of combined laser acupuncture and desmopressin in managing patients with NE to compare with their efficacy when used as monotherapy. The study included 186 patients. They were randomized into three equal groups. A statistically significant higher cure rate was reported in the group with a combination of laser acupuncture and desmopressin [13].

In Radvanska RCT study, a total of 31 patients with NE enrolled in the study. They compared laser acupuncture with placebo groups (control $1=$ red light and skin contact, and control $2=$ with red light without skin contact), but they found no significant effect of active laser acupuncture compared with placebo groups. They concluded that laser acupuncture is a safe but inefficient treatment for NE [14].

The Karaman RCT study was done with 91 children with NE. The children were randomized into two groups. They suggested that laser acupuncture therapy was significantly more effective compared to placebo in terms of complete dryness, partial improvement and a decrease in the mean number of weekly bedwetting episodes. This study suggested that laser acupuncture therapy can be considered as an alternative therapy for patients with NE [15].

In Yuksek study, 24 people enrolled. In this study, complete and partial responses in acupuncture group were seen in respectively $83.3 \%$ and $16.7 \%$ of patients treated with acupressure, after 6 months of treatment. In children who received oxybutynin, complete and partial responses were seen in respectively $58.3 \%$ and $33.3 \%$ of patients. They concluded that acupressure could be an alternative non-drug therapy for NE [16].

Honjo conducted a before-after clinical trial. They included 15 patients with NE who were treated by acupuncture. Nocturnal enuresis improvement rates were $40 \%$ just after the treatment and $47 \%$ two months after. They concluded that acupuncture may be useful in the treatment of nocturnal enuresis, and can be used an alternative therapy for NE [9].

Serel, $\mathrm{T}$ conducted a before-after clinical trial on 50 children suffering from NE. They showed that the efficacy of treatment was high. Within 6 months, 43 (86\%) had improvements. They suggested that using acupuncture in patients with NE appeared to be the most efficacious [10].

In Radmayr study, forty children with NE were enrolled. Then, the children were randomized into two groups: group A children were treated with desmopressin, and group B children took laser acupuncture. Response rate in group B was $65 \%$ but in group A was $75 \%$. Success rates indicated no statistically significant differences between two groups but they suggested that laser acupuncture should be considered as an alternative, noninvasive, painless, cost-effective, and short-term therapy for children with NE [17].

\section{Quantitative synthesis}

Only seven trials from five studies were included in meta-analysis because of disparity in outcome measures. Results are summarized in forest plot (Figure 1).

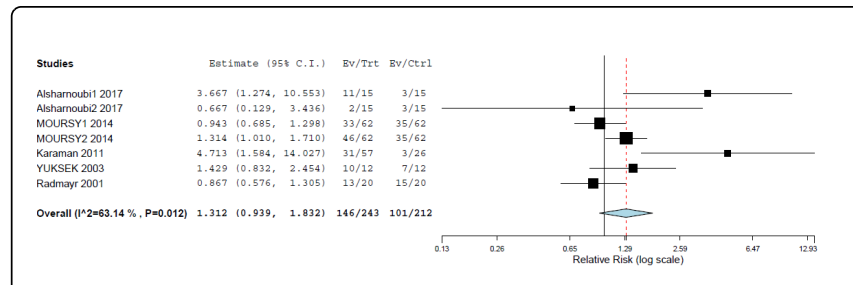

Figure 1: Forest plot of studies.

\section{Methods}

We searched PubMed, the Cochrane Library, Science Direct, Scopus, and Web of Science (updated on January 2017). Search terms were "(enuresis OR nocturnal enuresis OR nighttime urinary incontinence OR bedwetting) AND (acupuncture OR laser acupuncture OR electro acupuncture OR auricular acupuncture OR ear acupuncture OR scalp acupuncture OR acupoint OR moxibustion OR acupressure OR acustimulation)". We scanned bibliographies in relevant articles and conference proceedings. Studies by the same authors were checked for possible overlapping participant groups. If the study was reported as duplicate, only the most recent or complete study was included. Our selection criteria were:

(1) RCTs (randomized clinical trials) that used acupuncture as the only treatment or as an adjunct to other treatments, if they had been conducted in humans;

(2) Comparison of acupuncture treatment group with control group that take no acupuncture treatment for nocturnal enuresis. We had restrictions for translation from Chinese language, so we did not search Chinese databases. Studies that failed to meet the inclusion criteria were excluded.

\section{Data extraction and quality assessment}

Two independent reviewers extracted data from the articles according to the selection criteria. Disagreements were resolved by discussion between the two reviewers considering the opinion of a third reviewer. The quality of RCT studies was assessed using the Jaded score system.

The following information was abstracted from each included study: the first author and year of publication, design of study, sample size, mean age of patients, intervention regime, follow-up duration, and outcome measures for each group. All the analyses were based on previously published studies; thus, no ethical approval or patient consent was required.

\section{Quantitative data synthesis and data analysis}

We extracted data and then used comprehensive meta-analysis to pool them for summary estimates. We expressed the results with relative risk with $95 \%$ confidence intervals. We checked heterogeneity among our studies by the Chi-square-based Cochran's Q and I2 statistics to measure the proportion of total variation due to heterogeneity beyond chance. If I2 > 50\%, heterogeneity was considered statistically significant and data was analyzed using a random effect model. Otherwise, the fixed-effects model was applied as the preferred method. We used random effects model in this study, and in the whole study, $\mathrm{P}<0.05$ was considered as statistically significant. 
Citation: Azarfar A, Ravanshad Y, Aval SB, Khamnian S, Mehrad-Majd H (2017) A Systematic Review and a Meta-Analysis of Using Acupuncture for the Treatment of Nocturnal Enuresis. J Nephrol Ther 7: 292. doi:10.4172/2161-0959.1000292

Page 3 of 5

\section{Results}

\section{Search results and characteristics}

The literature search and reference mining yielded 508 potential relevant articles. We removed some articles because of duplication. We also excluded some articles after reviewing the titles and abstracts because they were books, book sections, review papers and therefore not relevant. Then, we reviewed full-text of selected articles and removed some other studies because their topics were not relevant to the subject. At last, remaining studies and trials were included in the systematic review (all of them were randomized clinical trial (RCT) except trial number 9 [9] and 10 [10] that were clinical trial beforeafter. The flow diagram of study selection is given in Figure 2. The main characteristics and the details of the studies are summarized in Table 1.

\begin{tabular}{|c|c|c|c|c|c|c|c|c|c|}
\hline Number & Name & Design & $\begin{array}{l}\text { Sample } \\
\text { size } \\
\text { case }\end{array}$ & $\begin{array}{l}\text { Sample } \\
\text { size } \\
\text { control }\end{array}$ & $\begin{array}{l}\text { Age } \\
\text { (mean) } \\
\text { case }\end{array}$ & $\begin{array}{l}\text { Age } \\
\text { (mean) } \\
\text { control }\end{array}$ & $\begin{array}{l}\text { Intervention } \\
\text { regime case }\end{array}$ & Intervention regime control & Follow-up (month) \\
\hline 1 & $\begin{array}{l}\text { Alsharnoubi } \\
\text { [11] }\end{array}$ & RCT & 15 & 15 & $8.8 \pm 3.18$ & $\begin{array}{ll}9.43 & \pm \\
2.77 & \end{array}$ & laser acupuncture & desmopressin acetate & 6 \\
\hline \multirow[t]{2}{*}{2} & $\begin{array}{l}\text { Alsharnoubi } \\
\text { [11] }\end{array}$ & RCT & 15 & 15 & $\begin{array}{ll}9.93 & \pm \\
3.16 & \end{array}$ & $\begin{array}{ll}9.43 & \pm \\
2.77 & \end{array}$ & laser acupuncture & desmopressin acetate & 6 \\
\hline & & & & & & & $\begin{array}{l}\text { desmopressin } \\
\text { acetate }\end{array}$ & & \\
\hline 3 & Mogahed [12] & RCT & 25 & 25 & $\begin{array}{ll}10.84 & \pm \\
3.31 & \end{array}$ & $\begin{array}{ll}10.28 & \pm \\
3.27 & \end{array}$ & laser acupuncture & sham laser & 1 \\
\hline \multirow[t]{2}{*}{4} & Moursy [13] & RCT & 62 & 62 & 15.6 & 15.9 & laser acupuncture & desmopressin acetate & 9 \\
\hline & & & & & $(10-21)$ & $(11-21)$ & & & \\
\hline \multirow[t]{2}{*}{5} & Moursy [13] & RCT & 62 & 62 & 15.8 & 15.9 & laser acupuncture & desmopressin acetate & 9 \\
\hline & & & & & $(11-21)$ & $(11-21)$ & $\begin{array}{l}\text { desmopressin } \\
\text { acetate }\end{array}$ & & \\
\hline \multirow[t]{2}{*}{6} & $\begin{array}{l}\text { Radvanska } \\
\text { [14] }\end{array}$ & RCT & 16 & 13 & 8 & 8.6 & laser acupuncture & $\begin{array}{lr}\text { CONTROL1: placebo } \\
\text { treatment with red light and } \\
\text { skin contact }\end{array}$ & 6 \\
\hline & & & & & $5-14$ & $5-16$ & & \begin{tabular}{ll} 
CONTROL2: & \multicolumn{2}{c}{ placebo } \\
treatment with red light \\
without skin contact
\end{tabular} & \\
\hline 7 & Karaman [15] & RCT & 57 & 26 & $8.5 \pm 3.2$ & $8.9 \pm 3.3$ & laser acupuncture & Non-laser light (placebo) & 6 \\
\hline 8 & Yuksek [16] & $\mathrm{RCT}$ & 12 & 12 & $\begin{array}{ll}7.67 & \pm \\
2.34 & \end{array}$ & $7.41 \pm 2.67$ & Acupressure & oxybutynin & 6 \\
\hline 9 & Honjo [9] & $\begin{array}{l}\text { CT before- } \\
\text { after }\end{array}$ & 15 & & & & acupuncture & & \\
\hline 10 & Serel [10] & $\begin{array}{l}\text { CT before- } \\
\text { after }\end{array}$ & 50 & & $\begin{array}{l}10.3 \quad(9- \\
18)\end{array}$ & & acupuncture & & 6 \\
\hline
\end{tabular}


Citation: Azarfar A, Ravanshad Y, Aval SB, Khamnian S, Mehrad-Majd H (2017) A Systematic Review and a Meta-Analysis of Using Acupuncture for the Treatment of Nocturnal Enuresis. J Nephrol Ther 7: 292. doi:10.4172/2161-0959.1000292

Page 4 of 5

\begin{tabular}{|l|l|l|l|l|l|l|l|l|l|}
\hline 11 & Radmayr [17] & RCT & 20 & 20 & $8(5-14)$ & $8.6(5-16)$ & laser acupuncture & desmopressin & 6 \\
\hline
\end{tabular}

Table 1: Characteristics of trials included in review.

\section{Outcome}

The disparity of outcome measures seen in trials is shown in Table 2.

\begin{tabular}{|c|c|c|c|c|c|c|c|}
\hline Number & Name & $\begin{array}{l}\text { Outcome1 } \\
\text { case }\end{array}$ & $\begin{array}{l}\text { Outcome1 } \\
\text { control }\end{array}$ & $\begin{array}{l}\text { Outcome1 } \\
\text { statistical } \\
\text { significance }\end{array}$ & $\begin{array}{l}\text { Outcome2 } \\
\text { case }\end{array}$ & $\begin{array}{l}\text { Outcome2 } \\
\text { control }\end{array}$ & $\begin{array}{l}\text { Outcome2 } \\
\text { statistical } \\
\text { significance }\end{array}$ \\
\hline 1 & Alsharnoubi [11] & $\begin{array}{l}\text { mean } \quad \text { value } \\
\text { bedwetting } \\
\text { frequency= } 1.13\end{array}$ & $\begin{array}{l}\text { mean value bedwetting } \\
\text { frequency }=5.8\end{array}$ & & $\begin{array}{l}\text { cure rate }=73.3 \%(11 \\
\text { of } 15)\end{array}$ & $\begin{array}{l}\text { cure rate }=20 \% \quad(3 \\
\text { of } 15)\end{array}$ & significant \\
\hline 2 & Alsharnoubi [11] & $\begin{array}{l}\text { mean } \quad \text { value } \\
\text { bedwetting } \\
\text { frequency=8.13 }\end{array}$ & $\begin{array}{l}\text { mean value bedwetting } \\
\text { frequency }=5.8\end{array}$ & & cure rate $=13.3 \%$ & cure rate $=20 \%$ & significant \\
\hline 3 & Mogahed [12] & $\begin{array}{l}\text { complete dryness } \\
=52 \%\end{array}$ & NR & significant & $\begin{array}{lr}\text { maximum } & \text { voiding } \\
\text { volume }= & 254.2 \quad \pm \\
63.86 & \end{array}$ & $\begin{array}{l}\text { maximum voiding } \\
\text { volume }=222.2 \pm \\
37.31\end{array}$ & significant \\
\hline 4 & Moursy [13] & $\begin{array}{l}\text { Cure with no bed } \\
\text { wetting=33(53\%) }\end{array}$ & $\begin{array}{l}\text { Cure with no bed } \\
\text { wetting }=35(56.5 \%)\end{array}$ & not significant & $\begin{array}{l}\text { maximum voiding } \\
\text { volume }=340 \pm 47.04\end{array}$ & $\begin{array}{l}\text { maximum voiding } \\
\text { volume }=286 \pm 27.7\end{array}$ & not significant \\
\hline 5 & Moursy [13] & $\begin{array}{l}\text { Cure with no bed } \\
\text { wetting }=46(74 \%)\end{array}$ & $\begin{array}{l}\text { Cure with no bed } \\
\text { wetting }=35(56.5 \%)\end{array}$ & significant & $\begin{array}{lr}\text { maximum } & \text { voiding } \\
\text { volume }=346 \pm 42.49\end{array}$ & $\begin{array}{l}\text { maximum voiding } \\
\text { volume }=286 \pm 27.7\end{array}$ & not significant \\
\hline 6 & Radvanska [14] & & & Not significant & $\begin{array}{l}50 \% \text { reduction of } \\
\text { wet nights } 3 \text { of } 16\end{array}$ & $\begin{array}{l}50 \% \text { reduction of } \\
\text { wet nights' control } \\
1+2=1 \text { of } 13\end{array}$ & not significant \\
\hline 7 & Karaman [15] & $\begin{array}{l}\text { the mean number of } \\
\text { bed-wetting episodes } \\
1.7 \text { per week }\end{array}$ & $\begin{array}{l}\text { the mean number of bed- } \\
\text { wetting episodes } \\
3.1 \text { per week }\end{array}$ & significant & $\begin{array}{l}\text { complete } \\
\text { improvement } \\
54.4 \%(31)\end{array}$ & $\begin{array}{l}\text { complete } \\
\text { improvement } \\
11.5 \%(3)\end{array}$ & significant \\
\hline 8 & Yuksek [16] & $\begin{array}{l}\text { complete responses } \\
83.30 \%\end{array}$ & $\begin{array}{l}\text { complete responses } \\
58.30 \%\end{array}$ & & & & \\
\hline 9 & Honjo & & & & $\begin{array}{l}\text { complete cure rate } \\
47 \%(7 / 15)\end{array}$ & & \\
\hline 10 & Serel T [10] & $\begin{array}{l}\text { completely dry } \\
43(86 \%)\end{array}$ & & & & & \\
\hline 11 & Radmayr [17] & & & & $\begin{array}{l}\text { response rate } \\
13(65 \%)\end{array}$ & $\begin{array}{l}\text { response rate } \\
15(75 \%)\end{array}$ & \\
\hline
\end{tabular}

Table 2: Outcome of trials.

\section{Discussion}

This study showed that there is no sufficient evidence to use acupuncture for treatment of NE. We found only seven trials that fulfilled our inclusion criteria. All of the studies had a control group except two $[9,10]$. The Mean ages of participants in all studies were between 7 to 11 years old except in MOURSY [13] study which was 15 years old. All the studies recommended the acupuncture as an alternative therapy for NE. We saw some disparity in sample sizes in found studies. Due to disparity in outcome measures, only seven trials from five studies were included in meta-analysis. We combined complete improvement percentage results of selected studies, and as can be seen in Figure 2, we calculated the heterogeneity $(0.12=63.14 \%$, $\mathrm{p}=0.012)$ ), so we used random effect model for this study. The final relative risk (RR) was not statistically significant (RR (range) = 1.312(0.939-1.832)), but evidence from independent review of each study suggested effective roll of acupuncture in treatment of NE.

A systematic review was done and evaluated the effectiveness of acupuncture for NE. In this study, randomized controlled trials which compared acupuncture therapy and pharmacological therapy or placebo treatment were identified, and a meta-analysis was performed. The results of meta-analysis of this study showed that acupuncture therapy is more effective for clinical efficacy when compared with placebo or pharmacological treatment, but this study suggested additional RCTs with rigorous experimental design, large-scale high 
Citation: Azarfar A, Ravanshad Y, Aval SB, Khamnian S, Mehrad-Majd H (2017) A Systematic Review and a Meta-Analysis of Using Acupuncture for the Treatment of Nocturnal Enuresis. J Nephrol Ther 7: 292. doi:10.4172/2161-0959.1000292

Page 5 of 5

quality methodological control, long follow-ups, and strict reporting specification [6]. Another systematic review was done about acupuncture for nocturnal enuresis in children. In that study, 11 studies were eligible for data extraction. That study suggested that acupuncture is useful for nocturnal enuresis when used in conjunction with other treatment (OR 3.98, CI: 2.2-7.2). They expressed that further rigorous studies were needed [18].

\section{Limitation}

A limitation of our study was that we could not search any Chinese database, and we therefore excluded some Chinese articles that didn't have English Translation because Chinese translator was not available and there was no budget for that. Another limitation is that the number of studies included is small, as well as the number of studies in the subgroup meta-analysis.

\section{Suggestion}

To find a definitive answer for this research question, further rigorous research is needed. Future studies should investigate the effects and safety of acupuncture types for treatment of NE.

\section{Conclusion}

In summary, the results of this study show that acupuncture seems to be an effective treatment for NE, but further large randomized trials are suggested.

\section{References}

1. Brittner M, Le Pertel N, Gold MA (2016) Acupuncture in Pediatrics. Curr Probl Pediatr Adolesc Health Care 46: 179-183.

2. Kemper KJ, Sarah R, Silver-Highfield E, Xiarhos E, Barnes L, et al. (2000) On pins and needles? Pediatric pain patients' experience with acupuncture. Pediatrics 105: 941-947.

3. Neveus T, Eggert P, Evans J, Macedo A, Rittig S, et al. (2010) Evaluation of and treatment for monosymptomatic enuresis: A standardization document from the international children's continence society. J Urol 183: 441-447.

4. Naseri M, Hiradfar M (2012) Monosymptomatic and nonmonosymptomatic nocturnal enuresis: A clinical evaluation. Arch Iran Med 15: 702-706.
5. Weaver A, Dobson P (2007) Nocturnal enuresis in children. J Fam Health Care 17: 159-161.

6. Lv ZT, Song W, Wu J, Yang J, Wang T, et al. (2015) Efficacy of acupuncture in children with nocturnal enuresis: A systematic review and metaanalysis of randomized controlled trials. Evidence-Based Complementary and Alternative Medicine.

7. Esposito M, Gallai B, Parisi L, Roccella M, Marotta R, et al. (2013) Primary nocturnal enuresis as a risk factor for sleep disorders: An observational questionnaire-based multicenter study. Neuropsychiatr Dis Treat 9: 437-443.

8. Kiddoo D (2015) Nocturnal enuresis: non-pharmacological treatments. BMJ Clin Evid.

9. Honjo H, Kawauchi A, Ukimura O, Soh J, Mizutani Y, et al. (2002) Treatment of monosymptomatic nocturnal enuresis by acupuncture: A preliminary study. Int J Urol 9: 672-676.

10. Serel TA, Perk H, Koyuncuoglu HR, Kosar A, Celik K, et al. (2001) Acupuncture therapy in the management of persistent primary nocturnal enuresis--preliminary results. Scand J Urol Nephrol 35: 40-43.

11. Alsharnoubi J, Sabbour AA, Shoukry AI, Abdelazeem AM (2017) Nocturnal enuresis in children between laser acupuncture and medical treatment: A comparative study. Lasers in medical science 32: 95-99.

12. Mogahed HGH, Borhan WH, Sowar SAG, Mohamed AH (2016) Response of bladder reservoir function to low level laser acupuncture in primary monosymptomatic nocturnal enuresis. International Journal of PharmTech Research 9: 30-39.

13. Moursy EES, Kamel NF, Kaseem AF (2014) Combined laser acupuncture and desmopressin for treating resistant cases of monosymptomatic nocturnal enuresis: A randomized comparative study. Scand J Urol 48: 559-564.

14. Radvanska E, Kamperis K, Kleif A, Kovacs L, Rittig S (2011) Effect of laser acupuncture for monosymptomatic nocturnal enuresis on bladder reservoir function and nocturnal urine output. J Urol 185: 1857-1861.

15. Karaman MI, Koca O, Küçük EV, Öztürk M, Güneş M, et al. (2011) Laser acupuncture therapy for primary monosymptomatic nocturnal enuresis. J Urol 185: 1852-1856.

16. Yuksek MS, Erdem AF, Atalay C, Demirel A (2003) Acupressure versus oxybutinin in the treatment of enuresis. J Int Med Res 31: 552-556.

17. Radmayr C, Schlager A, Studen M, Bartsch G (2001) Prospective randomized trial using laser acupuncture versus desmopressin in the treatment of nocturnal enuresis. Eur Urol 40: 201-205.

18. Bower WF, Diao M, Tang JL, Yeung CK (2005) Acupuncture for nocturnal enuresis in children: A systematic review and exploration of rationale. Neurourol Urodyn 24: 267-272. 